\title{
STRATEGIES TO ADDRESS THE BUREAUCRATIC DISENTITLEMENT OF CLIENTS FROM CULTURAL MINORITY GROUPS
}

\author{
ELI TERAM \\ Wilfrid Laurier University \\ and \\ HEATHER WHITE \\ United Way of Calgary and Area
}

\begin{abstract}
Based on studies conducted in Ontario and experience from Alberta, this paper describes the politics of bureaucratic disentitlement with respect to the delivery of social services to new Canadians. Interorganizational theory is applied to explain the dynamics that sustain service delivery strategies which have been consistently recognized as inappropriate. This discusion provides at base for rejecting strategies that delegate service delivery to specialized organizational units or to ethno-specific agencies. An approach that acknowledges both technical and political aspects of making social services responsive to the change in Canada's ethnic mix is outlined. The essence of this approach is to mandate networks of newcomer-serving agencies to negotiate and monitor appropriate adjustments by mainstream organizations to address the needs of culturally diversified communities.
\end{abstract}

A significant number of recent immigrants and refugees are excluded from receiving services from established health and social service organizations. Barriers are commonly attributed to language problems, lack of cross-cultural education, and limited knowledge of service delivery in a culturally sensitive way. Some potential clients do not seek help due to previous experience, misperception of programs, or lack of information about their availability. Others have difficulty coping with the unfamiliar and formal culture of the organizations. Thus, although Canada formally endorses multiculturism, people from cultures other than those traditionally served by human service organizations become victims of what Lipsky (1984) calls "bureaucratic disentitlement."

Bureaucratic disentitlement is a mode of retrenchment that takes place through the obscure and routine actions of public authorities and through their failure to take action (Lipsky, 1984). Lipsky points out that bureaucratic disentitlement, as well as its distributive consequences, is subtle; it "represents developments, intended or unintended, that erode the position of relatively powerless groups with-

\footnotetext{
A version of this paper was presented at the Fifth Conference on Social Welfare Policy, Bishop's University, Lennoxville, Quebec. August 25-28, 1991. Our thanks to the Journal's anonymous reviewers
for the for their comments on an earlier draft. The work on this article was supported by a grant from Wilfrid Lataricr University's Research Grants Program. For further information regarding the Calgary programs. Please contact Carole Holmes, Multicultural Facilitator. United Way of Calgary and Area, 120-13 Avenue S.E., Calgary, AH.
} 
out arousing them or their watch dog allies" (1984, p. 20). Since these practices take place behind closed doors, public policies like multiculturism may become ineffective, without prompting an open discussion of their shortcomings.

Such a discussion has also been delayed because of the overlap of federal and provincial government ministries responding to the needs of newcomers. Most government funding to settlement services comes from the Canada Employment and Immigration Commission through its Immigrant Settlement and Adaptation (ISAP) fund. Although services for immigrants have evolved to a recognition of the validity of seulement services, their purpose is unchanged: "They exist to facilitate entry of immigrants into the labour force, enabling them to become self-supporting and active participants in the labour market" (Allmen, 1990, p. 201).

Since health and social programs fall under provincial jurisdiction, ISAP's. funding criteria exclude services such as social and personal counselling. The Secretary of State and provincial funding sources for settlement services, like Ontario's Ministry of Citizenship, are also reluctant to support such counselling. When provincial ministries like the Ministry of Health and the Ministry of Community and Social Services in Ontario do allocate funds for counselling immigrants, these are given mostly to ethnic organizations, not settlement agencies, because the latter deal with "immigration"-a responsibility of the federal government (Allmen, 1990).

Funding for social support programs is also limited because mainstream organizations are expected to offer counselling and other "soft" services as part of their service to community members who satisfy their eligibility criteria. With responsibility for the delivery of government-mandated or -targeted services, these organizations consume the bulk of federal and provincial allocations for health and social programs, Immigrants, like other Canadians, are expected to take advantige of these programs, presumably receiving equal treatment and benefits.

Documentation of access to mainstream organizations for members of visible minority groups (e.g., Bidgood, Cameron, McMahon, \& Teram, 1989; Doyle \& Visano, 1987a,b) suggests, however, that this entitlement is yet to materialize. Although such reports deal with organizational practices, most of the conceptual discussion relates to social policy and community development issues (c,g. . Campfens, 1990; Jenkins, 1988) rather than to organizational theory. One notable exception is the work of Danet and her colleagues (e.g., Danet, 1971, 1973; Danet \& Gurevitch, 1972). Its implications for the improvement of service provision to new Canadians have been discussed by Teram (1990), with a focus on discretionary decision making at the "street level" (Lipsky, 1980), where clients and organizations interact. This paper considers the broader context of these organizational practices.

Based on studies conducted in Ontario and experience from Alberta, we first describe the politics of bureaucratic disentitlement with respect to the delivery of social services to new Canadians. Then, we apply interorganizational theory to explain the dynamics that sustain service delivery strategies which have been consistently recognized as inappropriate. This discussion establishes a base for an approach that acknowledges both technical and political aspects of making social services responsive to the change in Canada's ethnic mix. 


\section{THE DYNAMICS OF BUREAUCRATIC DISENTITLEMENT}

Lipsky (1980) identifies a variety of conditions which influence discretion in decision making, including ambiguous service goals and scarce resources. By maintaining broad policy statements, goveruments effectively pass along the decision-making power to the administrative and professional levels in a downward flow of discretion. Moreover, policies which are subject to competing interpretations create a situation whereby practically any kind of intervention can be justified (Handler, 1973). Although, in theory, discretionary power can benefit clients, it seems that for newcomers, it induces exclusion and the provision of limited or inappropriate services.

For example, both Bidgood et al. (1989) and Doyle and Visano (1987a,b) found a lack of written and verbally translated information resulting in reduced spending at many levels, including translation fees, printing costs, development of ethno-specific programs, staff training and, most importantly, the number of knowledgeable people who can demand service. When newcomers overcome these information barriers, agencies typically communicate with them through ad hoc interpretation-by family members, co-workers, friends, or neighbours. A study in five Ontario communities (Bidgood et al., 1989) identified many concerns with ad hoc interpretation arrangements, including questionable quality, lack of appreciation on the part of the interpreter of the agency's services and functions, lack of training and supervision of interpreters, difficulties with interference and biases affeeting translation, and issues related to confidentiality, reliability, and availability.

While expressing such concerns, public service agencies continue to rely on ad hoc provisions for interpreters. Several agencies considered volunteer interpreters a cost-saving measure. Convenience, rather than quality of service, was another motive for using volunteers. Similar factors seem to motivate short-staffed agencies, who allow cultural interpreters to assume the role of the service provider (Doherty Social Planning Consultants, 1988) ${ }^{1}$

Even when trained interpreters are available, they may be underemployed beeause workers tend to avoid or minimize contact with cases likely to handicap the attainment of measurable outcomes (Lipsky, 1980). Not surprisingly, the evaluations by Doherty Social Planning Consultants (1988) found that agency workers underuse Cultural Interpreter Access Programs (CIAP). Confusion over the role and need for cultural interpretation, combined with agency demands for efficiency, appeared to be the primary reasons. Thus, for instance, cultural interpreters were not employed if elients spoke enough English to complete the intake procedure, or the minimal process required for closing the case. Similarly, workers reported contact with clients with language barriers to be briefer than what was considered usual, with service provision often confined to the minimum required for satisfactory closure (Bidgood et al., 1989).

The use of interpreters may not be sufficient to alter current patterns of service delivery. For example, the establishment of CIAP in three communities did not significantly affect the nature of service provision for their users (Doherty Social Planning Consultants, 1988). The services provided through this program were mostly limited to short-term, emergency, essential, and/or mandated ones. Agencies useds cultural interpreters for intake, legal aid, medical examinations, 
and the similar "hard" services, whereas "soft" services, like long-term counselling, did not become more aceessible.

Similarly, formal interpretation services are typically established to serve the legal and quasi-legal systems, whereas social and health services must rely on volunteers, some of whom act as paid interpreters for the legal system (Bidgood et al. 1989). ${ }^{2}$ These discrepancies highlight the fact that bureaucratic disentitlement is more common where there is less risk of embarrassing exposures. Since the legal system is founded on due process, not having the provision of interpretation institutionalized would disturb the legitimacy of the system. By comparison, vague goals and technology in the social services allow for a wide range of substitutes for proper communication between clients and workers. Having to make do with inadequate resources, front-line workers "develop patterns of practice that tend to limit demand, maximize the utilization of available resources . . . and organize their work to derive a solution within the resource constraints they encounter" (Lipsky, 1980, pp, 82-83). Any account of these "patterns of practice" is bound to be incomplete because bureaucratic disentitlemenet involves subtleties known only to those who develop them. Thus, it is safe to assume that all these observations cover only a few of the methods for excluding newcomers from social programs that can ease the difficulties associated with integration into a new country. As we argue below, although this exclusion is not denied, the strategies for correcting the problem help perpetuate it.

\section{FORMAL RESPONSES TO BUREAUCRATIC DISENTITLEMENT}

Lipsky (1980) notes that powerful reference groups influence, define, and determine the role that public service agencies and workers will play in society. With the goals, functions, and role of public service agencies defined by the values of the majority, the operational criteria of agencies do not easily accommodate clients who do not belong to this group. Thus, while inaccessibility of mainstream organizations to newcomers has been documented, little effective change occurs in social policy and the service delivery system.

Most new immigrants settle in large urban centres, shifting the environment of human service organizations in these communities from a relatively homogenous client population to a heterogenous one. Contingency theorists suggest that, given beneficial economies of scale, organizations facing a diversified client population tend to split themselves into market-based units (Mintzberg, 1979). Following this theory, some organizations respond to the increased cultural diversity in the client population by developing a specialized unit for working with clients who are considered "different" from their traditional clientele. ${ }^{3}$ In some small communities. work with "ethnic" clients becomes, by design or default, the specialization of one or more workers.

This development may be considered a positive trend which reflects the sensitivity of these organizations to changes in their environment. Nevertheless, the formation of specialized units, or the delegation of "ethnic" clients to selected workers, may be yet another form of bureaueratic disentitlement. To be efficient. divisionalization requires the organization's technical core to split into segments that are replicated in each division. Unless such units represent all the specializations that exist within the organization, their creation means clients benefit only 
partially from the advantages associated with specialization. Since economies of scale likely preclude full representation of specializations in units providing "culthan a product of technical, their creation may be an attempt to look good rather proach, it may well become one of the institutionalized features organizations in clude in their structures to enhance the myth of responsiveness to change (Meyer \& Rowan, 1977).

There are, however, ways to respond to the cultural diversity of clients without limiting services to the specializations included in a "culturally responsive" unit. Instead of delegating service to selected workers, all workers may be expected to become sensitive to cultural diversity. To help sensitize them, organizations may hire workers to affect the work of others. As part of the organization's technostructure, these workers will be "removed from the operating work flowthey may design it, plan it, change it, or train the people who do it, but they do not do it themselves" (Mintzberg, 1979, pp. 29-30). One way to ensure that the establishment of such positions does not become another fictional solution is to delegate their responsibilities to outsiders, or to allow external input into the way an organization becomes culturally responsive. While ethno-specific organizations are ideal to fill this role, discussions have not resulted in significant changes (Campfens, 1990). In the following section, we examine the interorganizational dynamics underlying the obstacles to the relations between mainstream organizations and settement agencies.

\section{THE INTERORGANIZATIONAL CONTEXT OF DISENTITLEMENT}

The desired "partnership" between mainstream agencies and non-government organizations has been envisioned in different ways and articulated both by academics (c.g., Campfens, 1990) and government officials (e.g., Allmen, 1990). The common element of these visions is the belief that each set of organizations has strengths and weaknesses in providing services to immigrants. Accordingly, to improve services for newcomers, these organizations must complement each other, offering clients the benefit of both informal and formal service delivery systems. As Allmen (1990, p. 215) put it,

the relationship of mainstream agencies and settement service agencies has to change to a collaborative format in the future. Collegial partnership, a recognition of the expertise that exists on both sides and the utilization of this expertise for the well being of the person being helped, must be the paramount concern when developing services. The concept of equality between a mainstream professional agency and an agency staffed mainly with counsellors that are not labelled "professional" is quite innovative, somewhat threatening, but yet feasible.

The Ontario Ministry of Community and Social Services has been attempting to implement these concepts through the "bridging project." Interorganizational theory can help us speculate about the dynamics to be considered by those who attempt to build bridges between mainstream organizations and settlement agencies. 
Teram and Hines (1988, p. 324) summarize the three main frameworks for understanding the interactions between organizations-exchange, power dependence, and mandated basis.

All these frameworks suggest that interorganizational relations are formed only if the motivation to interact outweighs the motivation to remain autonomous. The exchange framework emphasizes the attainment of organizational goals and the acquisition of two scarce resources, money and authority, as reasons for exchanges in interorganizational networks (Benson, 1975; Levine \& White, 1961). The ability of a powerful organization to impose interaction on a weaker one is central for understanding interorganizational relations from the perspective of power-dependence (Schmidt \& Kochan, 1977). The mandated approach emphasizes the mandate to interact as the motive for developing these relations (Raelin, 1980),

These frameworks have been criticized for ignoring the dynamic element of interorganizational relations, including the use or inability to use one's initial position and resources to negotiate with other organizations (Crozier \& Thoenig. 1986; Milner, 1980). Applied to our discussion, these frameworks provide more questions than answers about the lack of collaboration between mainstream organizations and settlement agencies. If these organizations recognize they can attain their goals better by cooperating than by ignoring each other, why are there so few systematic exchanges between them? If the powerful can induce interaction, why don't mainstream organizations, with their superior resources, force settlement agencies to interact? If government can dictate collaboration between these organizations, why don't we have more mandated interorganizational cooperation?

A straightforward answer comes out of a case study of the interorganizational relations between rich and poor hospitals (Milner, 1980). After observing the dynamics that routed rich people to high-status hospitals and poor people to low-status ones, in spite of an attempt to reform the system, he offers the following conclusion:

An ideology of coordination, with an absence of mechanisms to produce it, contributes to the development of a stratified system of health institutions matching well our gut feelings about the type of service the poor should receive. Such an arrangement means our society can give such citizens the second-class service we privately feel they deserve while we blame the inatequacies of these services on lack of ceordination in the delivery system (p. 141 ).

One of the anonymous reviewers of this paper was not completely satisfied with this suggestion, arguing that if private prejudices are the cause of the problem, "then no amount of tinkering with funding and organizational mechanisms will solve it."

However, once we begin to expose these prejudices and discuss their consequences in terms of strategic choices, greater genuine effort may be expected in addressing the interorganizational dynamics underlying the bureaucratic disentitlement of newcomers. Interorganizational coordination is a complex issue even without the presence of prejudice against the people it is presumed to benefit. The essence of this complexity is captured by Alford and Friedland's (1985) summation of the internal contradictions within the state. These authors refer to contradictions within the bureaucratic aspect of the state as those between fragmentation and centralization; and to contradictions within the democratic aspects of the state as those 
between consensus and participation. Although the connection between the two sets of contradictions is not always visible, the capacity of the bureaucracy to function effectively is hampered by the need to accommodate the demands of various interest groups. The relative power of these groups, and their ability to detect and contest inappropriate responses to their needs, determine, in part, whose demands are accommodated and in what way.

Lack of concerted effort at both federal and provincial levels of government does not mean lack of initiatives to improve service provision to newcomers; however, these initiatives have been intermittent, disjointed, and sometimes contradictory. Thus, for example, Allmen's account (1990) of a systsem in need of interorganizational, interministerial, and intergovernmental coordination in service provision to immigrants was written almost two decades after Hawkins (1972) had made similar observations ${ }^{4}$ Another example is related to the common dilemma of funding bodies addressing requests for funding by ethnic organizations interested in developing services for members of their community. Arguments by these groups resemble those presented in the first section of this paper: mainstream organizations are not accessible and are not likely to deviate from routine to develop culturally responsive intervention strategies or mechanisms to address language barriers. The typical proposal is the development of parallel programs to provide what mainstream organizations fail to deliver. It is tempting to applaud these requests: they are modest and may provide a highly visible product of progressive multicultural policies. Thus, despite the tacit understanding that the development of parallel services is not desirable, such initiatives receive funding from a variety of sources.

While the investment of government in these ventures has to do with their relatively low cost, the dynamics behind the lack of organized opposition to this development by mainstream organizations are more complex. In theory, mainstream organizations should feel threatened by the takeover of services that fall under their jurisdiction: firstly, becuuse it is an intrusion into their domain; secondly. because it implies they are neither doing their job properly, nor trusted to adjust. However, this threat seems less significant than the benefits mainstream organizations may derive from the establishment of parallel programs by ethnic organizations. Like the poor hospitals in Milner's study (1980), ethnic organizations who provide parallel services can fulfil important functions for the more resourceful mainstream organizations. One function may be to provide a buffer between mainstream agencies and clients they are not interested to serve. Moreover, while providing a valuable escape from the need to adjust programs, ethno-specific service providers can also become a "warehouse" for keeping clients until these clients are needed to correct fluctuations in the demand for the specialized programs of mainstream organizations.s Like the rich hospitals in Milner's study, mainstream organizations can also assist ethno-specific organizations in dealing with issues that require high levels of specialization. ${ }^{6}$ Such exchanges would allow mainstream organizations both to maintain their superiority as experts and control the diversion of this expertise to serve clients who are too different from those for whom this expertise was developed. Thus, while cthno-specific organizations may be able to serve some clients better through developing parallel programs, this development may also control the demand for more comprehensive adjustments by mainstream Organizations. 
Another problem associated with the development of parallel programs by ethno-specific organizations has to do with the contradiction between this strategy and the concept of multiculturalism. As much as unchanged mainstream organiza. tions stand for assimilation, the establishment of a parallel system reinforces sepa. ration. If integration is the acculturation mode that a multicultural policy is to encourage, there must be a fundamental change in the strategy taken by government and other funding bodies.

\section{A PROPOSED STRATEGY AND MID-RANGE ALTERNATIVES}

The essence of the proposed strategy for bridging between mainstream organizations and newcomers includes the following:

- mainstream agencies are the target for change,

- ethno-specific and multicultural organizations provide input and services as a network rather than individually,

- the network is to be mandated as the formal representative of ethno-specific and multicultural organizations regarding the provision of services to newcomers,

- the network receives funding for establishing mechanisms to make mainstream organizations more accessible and responsive to the needs of newcomers. ${ }^{7}$

The first step toward the implementation of this approach is the establishment of coordination among funding sources and the standardization of funding criteria. Demands that service providers coordinate their programs will be taken more seriously when governments provide a role model. Thus, a forum for planning collective action by federal, provincial, and local governments, and other major funding bodies (e.g., the United Way) has both functional and symbolic value. The knowledge that funders do not consult each other underlies the motivation of agencies to withdraw from or not join interorganizational coalitions. Moreover, it results in the formation of small agencies with limited ability to respond to complex needs in an already fragmented field. Therefore, before mandating interorganizational networks, government and other funders must establish efficient mechanisms to respond to proposals generated by these networks.

Although we are not familiar with communities where the proposed strategy has been implemented, the United Way of Calgary and Area is involved in two projects that reflect incremental moves in the direction we outlined. Currently. these initiatives operate in a parallel but complementary manner. One project is The Multicultural Organizational Change/Partnership Grants Initiative; the second is a Bridging Project.

The Multicultural Organizational Change/Partnership Grants Initiative aims to help mainstream and various multicultural and ethno-specific organizations and groups work together to eliminate access barriers to social services in Calgary. It requires a two-year commitment by mainstream agencies to work toward: the dismantling of visible and invisible barriers to full social, political, and economic participation of all individuals, particularly people from traditionally non-dominant groups; and, the establishment of an organization that is responsive, responsible, 
and reflective of the entire community. Mainstream agencies who are engaged in Multicultural Organizational Change are eligible to apply for Partnership Grants. Applications must be submitted in partnership with a multicultural or an ethnospecific organization, fit with the mainstream agency's strategic direction, and be an integral part of its Multicultural Change process. The partners must indicate what impact they intend to achieve within the community and within their own organization. They must also point out why they require the assistance of the other to achieve the project's goals.

The Bridging Project was initiated as a response to increasing requests for funding by immigrant-serving agencies. Various funders from the federal, provincial, and local governments came together to compare funding and eligibility criteria with the intent of eliminating possible overlaps or gaps in funding. One of the goals of the Bridging Project is to engage service providers and immigrants, particularly those in the post-settlement stage, in the identification, planning and development of services needed for the Calgary community. Thus this project is set to accomplish the following objectives: establish a forum whereby various funders can review service proposals and assess if/how the projects might be funded; bring together the various players who might provide, or be interested in the provision of services to immigrants (e.g., settement agencies, immigrant-serving agencies, mainstream services, and ethno-specific groups); and establish a community committee to set priorities and make recommendations to the funders' group.

These two initiatives creatively combine elements from the exchange framework and the mandated approach for supporting collaboration between organizations; however, unlike the strategy we propose, they don't go far enough in terms of the development of a unified approach to service delivery and in terms of balancing the power diferentials between ethno-specific agencies and mainstream organizations. Although the terms in the Multicultural Organizational Change/Partnership Grants suggest equality between the partners, mainstream organizations have resources, like mandate and expertise, that are bound to define the direction of change. The network we propose can pool resources to purchase this expertise, something that individual organizations cannot do. Moreover, it is not clear how one ethno-specific agency or group can do justice to the diversity in the community. Although the Bridging Project brings together funders, thereby establishing one entry point for proposals, funding decisions are not based on a set of general criteria. Thus, some of the contradictions we discussed earlier may be perpetuated and endorsed by a body that has the potential to establish a unified service delivery approach. Furthermore, while the Bridging Project relies on consultation with the community, those who are consulted do not have the authority associated with representing a mandated network.

\section{CONCLUSION}

Ethno-specific organizations may be alarmed by the suggestion for eliminating funding for programs developed by individual agencies without consultation with a mandated network. However, these organizations and their funders must develop mutual trust to realize the benefits associated with a mandate to represent the needs of newcomers in a unified way. The present system of multiple ethno-specific programs does not, and will not, provide a substitute for the services provided by 
mainstream organizations. Politically, these programs provide a buffer for mainstream organizations and inhibit adjustment in the broader system. Moreover, these small agencies are not equipped with the kind of expertise to help primary groups influence large bureaucracies (Litwak, Shiroi, Zimmerman, \& Bernstein, 1970). To follow the arguments of these writers,

the bureaucracy can resist the community on changes in areas of expertise in the same way (it) selectively screens out messages in technical areas-the community lacks enough information to know what has to be changed, to know whether change has taken place or not, or to have the time for change to take place. Therefore we would suggest that to handle change in expert areas the community must have expert advocates (Litwak et al., 1970, p. 52).

The use of experts by ethno-specific organizations, as well as the employment of other mechanisms for influencing mainstream organizations cannot be handled effectively by individual organizations. It requires a pooling of resources, appropriate stratogies, and concerted efforts to identify areas requiring change and to target mainstream organizations systematically. While a full discussion of these strategies is beyond the scope of this paper, it is clear that their implementation requires funding of collective rather than disjointed actions.

Although there is little doubt that government has the ability to manipulate the infrastructure of service provision (Thompson, 1974), its motivation to move in the direction proposed in this paper is questionable. The issues presented here are not new and the problems of access and lack of coordination have been documented. Nevertheless, the field is characterized by contradicting practices at the local level guided by disjointed federal and provincial initiatives. Unless this reality is changed, we will have further evidence to support the argument that the perpetual call for coordination conceals the lack of political will to alter the status quo.

\section{NOTES}

1. For example, cultural interpreters were often left alone with consumers and expected to complete the intake process.

2. In some hospitals, the use of volunteers as interpreters is institutionalized in the form of listing the languages spoken by professional and non-professional employees (Bidgood et al., 1989).

3. Some family service agencies and child welfare organizations have units or individuals who work with families of specific ethnic groups.

4. Interestingly, the 1988 edition of Hawkin's book does not provide an update of the fate of her assignment by the Department of the Secretary of State to review its role in relation to immigrants; a task that included issues of intergoyernmental and inter-ministerial coordination and entails consultation with the provinces and with voluntary agencies.

5. See Rains \& Teram (1992) on organizational strategies to deal with fluctuations in the supply of elients.

6. In Milner's study, the rich hospitals allowed the poor ones to use their labs and $x$-ray facilities,

7. A more detiiled proposal is presented in McKenzie-Mohr, Teram, and McKenzie-Mohif (March, 1992). 


\section{RÉSUMÉ}

Se fondant sur des études mencés en Ontario et une expérience réaliséc en Alberta, cet article présente les politiques de "détitularisation" (disentitlement) appliquées dans la prestation de services sociaux aux nouveaux Canadiens, Une théorie interorganisationnelle est utilisée pour expliquer la dynamique soutenant les stratégies de prestation des services, lesquelles ont été régulièrement reconnues comme non appropriées. La présente analyse fonde le rejet de stratégies qui réferent la prestation des services à des unités organisationnelles spécialisées ou à des agences à définition ethnique. On met plutót de l'avant une approche qui reconnait les aspects à la fois techniques et politiques d'une pratique de services sociaux respectueuse du mélange ethnique canadien. L'essence de cette approche consiste à mandater les réseaux d'agences d'accueil des nouveaux venus pour qu'elles puissent obtenir et guider les ajustements nécessaires auprès des organisations habituelles de services afin qu'elles-mémes puissent rencontrer les besoins de communautés culturellement diversifiées.

\section{REFERENCES}

Alford, R.R., \& Friedland, R. (1985). Powers of theory. Cambridge: Cambridge University Press.

Allmen, E. (1990), "Counselling and settlement": The current and future role of mainstream and settlement services. In S.A. Yelaja (Ed.), Proceedings of the Sentement and Integration of New Immigrants to Canada Conference (pp. 199-222). Wilfrid Lauricr University, Faculty of Social Work and Centre for Social Welfare Studies, Waterloo, ON.

Benson, K.J. (1975). The interorganizational network as a political economy, Administrative Science Quarterly, 20, 229-249.

Bidgood, G., Cameron, G., McMahon, P., \& Teram, E. (1989, January). Cultural Interpreter Pilot Project Expansion Assessment. A research report submitted to the Ministry of Citizenship and Culture, Toronto, ON.

Campfens, H.C. (1990). The role and future of non-governmental organizations in settlement and integration. In S.A. Yelaja (Ed.), Proceedings of the Settlement and Integration of New Immigrants to Canada Conference (pp. 147-173). Wilfrid Laurier University, Faculty of Social Work and Centre for Social Welfare Studies, Waterloo, ON.

Crozier, M., \& Thoenig, J.C. (1986). The regulation of complex organized systems. Administrative Science Quarterly, 21, 547-570.

Danet, B. (1971). The language of persuasion in bureaucracy: "Moderns" and "Traditional" appeals to the Isracl customs authorities. American Sociological Review, 36, 847-859.

Danet, B. (1973). Giving the underdog a break: Latent particularism among custom officials. In E. Katz \& B. Danet (Eds.), Bureaucracy and the public: A reader in official-client relations (pp. 329-337). New York: Basic Books.

Danet, B., \& Gurevitch, M. (1972). Presentation of self in appeals to bureaucracy: An empirical study of role specificity. American Joumal of Sociology, 77, 1165-1190.

Doherty Social Planning Consultants. (1988, June). The process evaluation of cultural interpreters rentres. (Three reports focusing on the process in three Ontario communities.) Toronto: Author,

Doyle, R., \& Visano, L.A. (1987a). A time for action. Toronto: Social Planning Council of Metropolitan Toronto.

Doyle, R., \& Visano, I. A. (1987b). A program for action. Toronto: Social Planning Council of Metropolitan Tononto.

Handler, J.F. (1973). The coercive social worker. Chicago: Rand McNally College.

Hawkins, F. (1972). Canada and immigration. Montreal: McGill-Queen's University Press. 
Jenkins, S. (Ed.). (1988). Ethnic associations and the welfare state. New York: Columbia University Press.

Levine, S., \& White, P.E. (1961). Exchange as a conceptual framework for the study of interorganizational relations. Administrative Science Quarterly, 5, 583-601.

Lipsky, M. (1980). Street-level bureaucracy. New York: Russell Sage Foundation. Lipsky, M. (1984). Bureaucratic disentitlement in social welfare programs. Social Service
Review, 58, 3-27.

Litwak, E., Shiroi, E., Zimmerman, L., \& Bernstein, J. (1970). Community participation in bureaucratic organizations: Principles and strategies. Interchange, I(4), 44-60.

McKenzie-Mohr, D., Teram, E., \& McKenzic-Mohr, S. (1992, March). Communty needs assessment and review of the nenvork of newcomer-sening agaencies of Windsor-Ersex County. Unpublished report submitted to the Network of Newcomer Serving Agencies of Windsor-Essex County.

Meyer, J.W., \& Rowan, B. (1977). Institutionalized organizations: Formal structure as myth and ceremony. American Joumal of Sociology, 83, 340-363.

Miner, M. (1980). Unequal care. New York: Columbia University Press. Mintzberg, H. (1979). The structuring of organizations. Englewood Cliffs, NJ: Prentice-
Hall.

Rains, P., \& Teram, E. (1992). Normal bad boys. Montreal: McGill-Queen's University
Press.

Raclin, J.A. (1980), A mandated basis of interorganizational relations: The legal-political network. Human Relations, 33, 57-68.

Schmidt, S.M., \& Kochan, T.A. (1977). Interorganizational relationships: Patterns and motivations. Administrative Science Quarterly, 22, 220-234.

Teram, E. (1990). Encounters between immigrants and formal organizations in Israel: Lessons for Canada. In S.A. Yelaja (Ed.), Proceedings of the Settlement and Integration of New Immigrants to Canada Conference (pp, 65-82). Wilfrid Laurier University, Faculty of Social Work and Centre for Social Welfare Studies, Waterloo, ON.

Teram, E, \& Hines, P. (1988). The case for government involvement in the management of cutbacks by public service organizations. Canadian Public Administration, 31, 321-334.

Thompson, J. (1974). Social interdependence, the polity and public administration. Administration and Society, 6, 3-19. 